\title{
O PROCESSO DE URBANIZAÇÃO E AS MUDANÇAS NA CIDADE DE FEIRA DE SANTANA
}

\author{
Maria Carolina da Anunciação Nascimento' Janio Santos $^{2}$
}

\author{
1.Bolsista CNPq/FAPESB, graduanda em Geografia, Universidade Estadual de Feira \\ de Santana, e-mail: carol.anunciacao@live.com
}

\author{
2.Janio Santos, Doutor em Geografia, Professor Titular/DCHF-UEFS, e-mail: \\ janiosantos@yahoo.com.br
}

\section{INTRODUÇÃOO}

O propósito deste trabalho é pensar os fatores/dinâmicas que, aliados às alterações na lógica da urbanização capitalista, no decorrer dos anos, fizeram com que a Feira de Santana se constituísse enquanto uma cidade média, isso se pensarmos nas características e importância que o município adquiriu nas últimas duas décadas no contexto da urbanização baiana. Com tais discussões, torna-se possível avançar na compreensão sobre as transformações que vêm ocorrendo na produção das cidades médias localizados na Bahia e contribuir para a reflexão sobre como o avanço das relações capitalistas no Brasil alterou a vida e a dinâmica urbanas.

Sendo assim, percebe-se que, a partir de um dado momento em sua constituição como cidade média, o comércio enraizado e os serviços implantados passaram a ter papel determinante para os rumos que tomaria; e esse processo, além de trazer a industrialização, maior infraestrutura e maiores planejamentos, evidenciou problemas sociais e enalteceu diversas formas de desigualdades em seu território urbano.

Com base nessa problemática, argumenta-se que o nexo deste trabalho é pensar os fatores/dinâmicas que, aliados às alterações na lógica da urbanização capitalista, fizeram com que a Feira de Santana se constituísse enquanto uma cidade média, isso se pensarmos nas características e importância que essa adquiriu nas últimas duas décadas no contexto da urbanização baiana. Com tais discussões, torna-se possível avançar na compreensão sobre as transformações que vêm ocorrendo na produção das cidades médias localizados na Bahia e contribuir para a reflexão sobre como o avanço das relações capitalistas no Brasil alterou a vida e a dinâmica urbanas.

Palavras chave: Dinâmica, Processos, Centro, Feira de Santana.

\section{METODOLOGIA}

Levantamentos para pesquisa cartográfica e bibliográfica, que buscaram informações que trataram a urbanização de Feira de Santana e das cidades médias; pesquisa documental, parte importante, relacionada à coleta do material existente sobre a história, feita em órgãos e acervos históricos do município, bem como em sites oficiais; sistematização das informações coletadas, para organização dos dados coletados e elaboração de quadros, tabelas e mapas. A análise teve como fito desvelar as contradições engendradas no sistema capitalista, e torna-se imprescindível, para nossas 
pretensões, analisar as mudanças ocorridas na cidade articuladas aos princípios teóricos e metodológicos do Materialismo Histórico e Dialético.

\section{ANÁLISE E DISCUSSÃO DOS RESULTADOS}

Segundo Souza (2005), "[...] as cidades surgem como resultado de transformações gerais - econômicas, tecnológicas, políticas e culturais." o que nos leva a entender a concepção de Cristaller sobre a conceituação da mesma, tratando-a como uma localidade central, que, por sua vez, seguindo o ponto de vista geoeconômico, possui um nível de espacialidade maior ou menor de acordo com os bens e serviços que ela oferta. Ou seja, caracteriza-se por localiza-se em um espaço que possui infraestrutura que permita a oferta de serviços que sejam essenciais para a orientação do município.

Sposito (2004) assegura que, num longo processo espaço-temporal, as cidades obedecem a um crescimento e práticas que incentivam às atividades industriais e/ou comerciais, a qual a autora nomeia como urbanização. Esse fato representa a ampliação dos bens e serviços oferecidos, o qual abre espaço para o aumento populacional e de serviços secundários, da industrialização e melhor infraestrutura do local.

A recente estrutura de Feira de Santana é resultado desse processo mencionado por Sposito (2004), de cunho social e estrutural, que afetou toda a dinâmica do antigo arraial, transformando-o em uma cidade média. Se deu como produto da urbanização; ou seja, é o resultado das relações sociais, de mercado, tecnológico, político e espaciais, que, em conjunto, atuam como determinantes essenciais na sua formação.

Feira de Santana encontra-se localizada na zona de planície entre o recôncavo e os tabuleiros semiáridos do nordeste baiano, distando aproximadamente a 116,2 $\mathrm{Km}$ da capital Salvador, partindo pela BR-324. Situa-se no entroncamento com as BR's 101, 116 e 324, o que acarretou na criação de um ponto de ligação para o tráfego que vem do Sul e do Centro Oeste, em direção a Salvador e outras importantes cidades nordestinas. Além disso, a cidade possui uma área territorial de 1337, $993 \mathrm{~km}^{2}$ e segundo o senso de 2015, a população estimada é de 517.528 habitantes (IBGE, 2010). (Mapa 1)

Teve origem no início do século XVIII, na fazenda Santana dos Olhos D`Água, que pertencia aos portugueses Domingos Barbosa de Araújo e Ana Brandoa. Nessa, os proprietários construíram uma capela que, no entorno, deu início a uma povoação e posteriormente, uma feira tornando-se um "centro de permuta comercial".(IBGE, 1958). Feira de Santana reconhecida pelo IBGE como cidade média e, durante o andamento para se tornar uma cidade que abrange tanto o comércio quanto os serviços, funcionava como espécie de sistema urbano dominante - no qual, mesmo tendo características de uma cidade autossuficiente, tinha dependência da capital Salvador - e em decorrência por "adotar" esse sistema, passa a realizar significativas tarefas nos âmbitos interurbano e intraurbano, através dos serviços e do comércio que a cidade passou a dispor.

Ainda também seguindo os dados do IBGE, o Produto Interno Bruto (PIB), que diz respeito ao total de valores contabilizados a partir dos bens e serviços produzidos por pela cidade, desde pouco mais de 60 anos atrás, já concentra sua maior intensidade de valores no setor terciário de produção como mostra a tabela 1 . 
Mapa 1 - Localização de Feira de Santana na Bahia, 2016

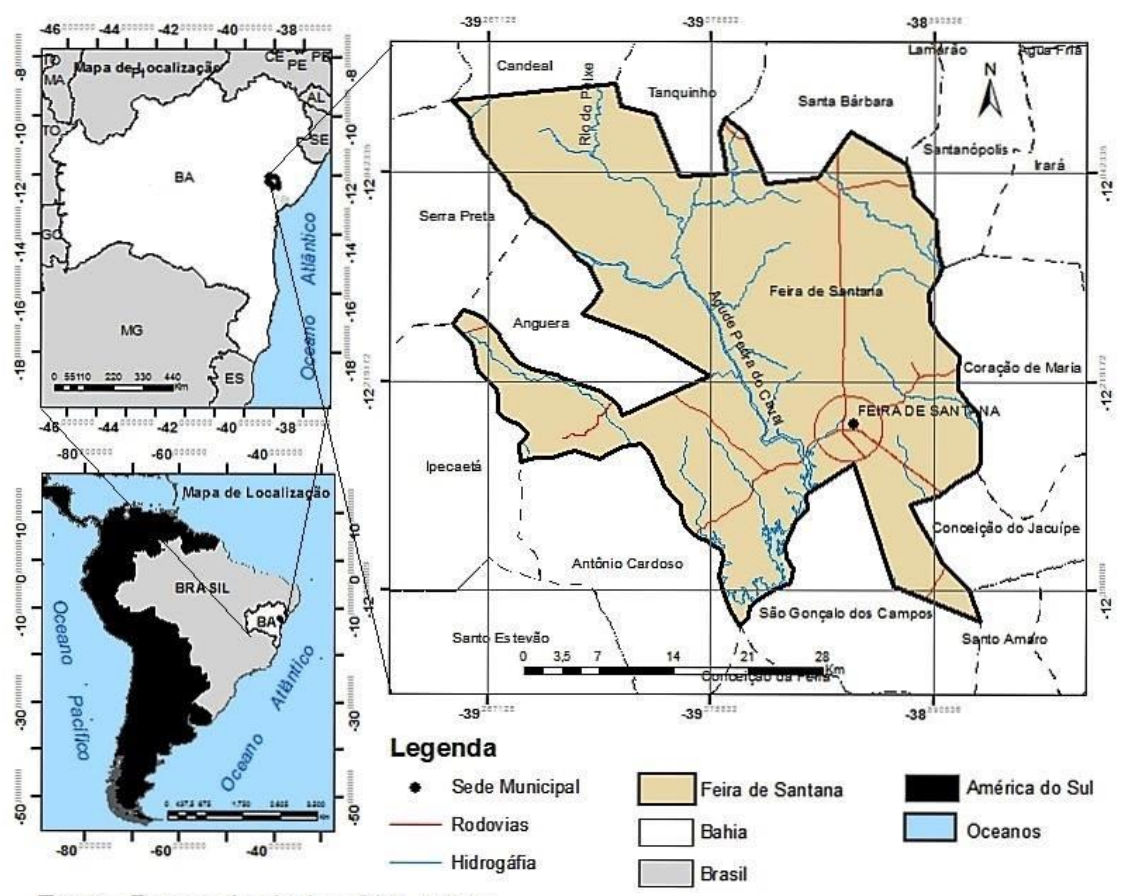

Fonte: Banco de dados SIG, IBGE

Datum: SIRGAS 2000,

Elaboração: BRITTO, Ákila Soares de, 2016

Tabela 1:

Tabela do PIB Por Setores de Feira de Santana, 1949-2012

\begin{tabular}{c|c|c|c}
\hline \hline \multirow{2}{*}{ Anos } & \multicolumn{3}{|c}{ Setores } \\
\cline { 2 - 4 } & Primário & Secundário & Terciário \\
\hline \hline 1949 & 19,74 & 8,32 & 71,93 \\
1959 & 7,65 & 16,94 & 75,42 \\
1970 & 7,63 & 26,48 & 65,89 \\
1980 & 2,86 & 37,33 & 59,81 \\
1990 & 0,92 & 16,69 & 82,39 \\
2000 & 0,91 & 20,19 & 78,90 \\
2012 & 0,56 & 26,03 & 73,41 \\
\hline \hline
\end{tabular}

Fonte: IBGE, 1949, 1959, 1970, 1980, 1990, 2000 e 2012.

Mesmo possuindo grandes áreas rurais, o município não mais depende exclusivamente da agropecuária para manter a circulação do capital. Além disso, evidencia que os serviços e o comércio ganham mais notoriedade, uma vez que mesmo possuindo grandes indústrias em seu território o setor terciário ainda é o que mais se destaca.

A tabela 2 elucida o percentual de incremento médio anual, decenal e de dados absolutos referentes à população residente em Feira de Santana, desde o ano de 1940 até o ano de 2010. Assim sendo, nota-se que, segundo os dados percentuais, o ritmo de crescimento geométrico anual e o incremento decenal foram decaindo gradualmente a partir de 1960; em contrapartida, os valores dos dados absolutos ou a taxa de incremento oscilaram e só passara a reduzir a partir de 1991. 
Tabela 2-Feira de Santana: Taxa de crescimento geométrico anual, Taxa de crescimento decenal e Incremento da população da cidade ${ }^{1}, 1940-2010$

\begin{tabular}{|c|c|c|c|}
\hline \multirow[b]{2}{*}{ Períodos } & \multicolumn{2}{|c|}{ Dados Percentuais } & \multirow{2}{*}{$\begin{array}{c}\text { Dados Absolutos } \\
\text { Crescimento } \\
\text { absoluto } \\
\end{array}$} \\
\hline & $\begin{array}{c}\text { Crescimento } \\
\text { geométrico anual }\end{array}$ & $\begin{array}{c}\text { Crescimento } \\
\text { decenal }\end{array}$ & \\
\hline 1940-1950 & 6,51 & 87,95 & 12.428 \\
\hline 1950-1960 & 9,95 & 158,28 & 42.037 \\
\hline 1960-1970 & 6,35 & 85,10 & 58.376 \\
\hline 1970-1980 & 5,98 & 78,78 & 100.032 \\
\hline 1980-1991 & 3,76 & 50,05 & 113.617 \\
\hline 1991-2000 & 2,35 & 23,25 & 79.195 \\
\hline $2000-2010$ & 1,68 & 18,14 & 76.149 \\
\hline
\end{tabular}

Fonte: IBGE (1940, 1950, 1960, 1970, 1980, 1991, 2000 e 2010).

O município possui o Centro Industrial do Subaé, ocupa a segunda maior posição em população e de polo de seu estado, uma universidade estadual (UEFS), um campus da Federal (UFRB) e mais seis particulares (FAN, FAT, ENEB, FTC, UNEF e FUFS), um aeroporto de pequeno porte, hospital regional, da criança e da mulher, Bancos públicos e particulares, hipermercados, atacadões, shoppings, indústrias de grande e pequeno porte, conjuntos habitacionais, transbordos e um grande terminal rodoviário.

Tais atrativos chamam atenção das cidades pequenas de seu entorno, no qual encontra os serviços - comerciais ou não - que a cidade de Feira de Santana oferece, evidenciando assim seu papel de cidade regional. Além disso, nos remete lembrar da sua antiga conjuntura, mesmo sendo um centro de permutas as cidades em seu entorno se voltava para Feira de Santana para que pudessem vender ou comprar na feira local.

\section{CONSIDERAÇÕES FINAIS}

Ao observa Feira de Santana como cidade média percebe-se a importância no seu papel enquanto polo regional, que, além de possuir dinâmica econômica e demográfica própria, atende às necessidades do setor terciário dos cidadãos, se tornando visível nas opções dos equipamentos urbanos e serviços públicos que dispõe.

Espera-se o conhecimento de como se estabeleceu o processo de urbanização em Feira de Santana, centrado no estudo sobre as mudanças na estrutura urbana, para construir acervo de dados, mapas e informações que contribuam para explicar a realidade e favorecer a implantação de políticas ao planejamento e para subsidiar outros estudos.

\section{REFERÊNCIAS}

INSTITUTO BRASILEIRO DE GEOGRAFIA E ESTATÍSTICA (IBGE).

Enciclopédia dos Municípios Brasileiros. Rio de Janeiro: IBGE, 1958. Volume XX. . Censo Demográfico, 2010. Disponível em:

<http://www.ibge.gov.br/censo2010/>, acesso: 10 abr. 2016.

SOUZA, M. L. de. ABC do desenvolvimento urbano, $2^{\mathrm{a}}$ Ed. Rio de Janeiro: Bertrand Brasil, 2005.

SPOSITO, M. E. B. O chão em pedaços: urbanização, economia e cidades no Estado de São Paulo, 2004. 504f. Tese (Livre Docência) - Faculdade de Ciências e Tecnologia, Universidade Estadual Paulista, Presidente Prudente, 2004. 